\title{
Statistics of the early synthetic dye industry
}

\author{
Eric Hagan * (D) and Jennifer Poulin (1)
}

\begin{abstract}
From the invention of Perkin's Mauve in 1856, to publication of the first edition of the Colour Index in 1924, more than 1200 synthetic organic colourants were introduced. Some achieved commercial success, while others were rarely used for reasons such as high cost, low fastness, and toxicity. This turbulent period of innovation was largely driven by demand of the textile industry; however, synthetic colourants were subsequently adopted in many other applications. An understanding of the most common materials and their properties is therefore important to the study of heritage collections and their preservation. The risk of light damage during exhibition of objects is often a concern due to the fugitive nature of many synthetic colourants.

To provide a foundation for focused research on synthetic dye identification and lightfastness, work was carried out to identify the most prominent of these colourants used in North America up to the year 1924 when the first edition of the Colour Index was published. Information was compiled and analysed from several sources including multiple editions of the Colour Index, and government documents related to the manufacture and trade of synthetic dyes that provide data from 1914 onwards. Cross-referencing between the information sources provided a summary of parameters for each colourant including the date of introduction, number of manufacturers, lightfastness, and quantity produced or imported in the United States.

A document published in 1916 by the US Department of Commerce listed 259 colours with Schultz number imported during the 1913-1914 fiscal year, in quantities above 10,000 lb (4536 kg). Adding domestic products to the list, and removing duplicates, gave 289 individual colours with Schultz number imported and/or produced in the US. In addition, there were some imports of unknown composition: 96 azo, 23 sulphur, and 68 unclassified. Further review of census data from 1917 through the 1920's suggested that less than one quarter of the dyes listed in the Colour Index were imported or manufactured in significant amounts. The results of this analysis are presented as summary statistics, which are complemented by an open dataset publication to facilitate future research.
\end{abstract}

Keywords: Synthetic dyes, Identification, Lightfastness

\section{Introduction}

Early advances related to synthetic and semi-synthetic dyes were made by Barth (indigo carmine, 1743) [1], Woulfe (picric acid, 1771) [2], Scheele (murexide, 1776) [3], and Runge (aurin, 1834) [2, 4]; however, a commercial industry was not significant until William Perkin created mauveine in 1856 . This was followed by a period of accelerated developments of new products, which peaked near the end of the 19th century. Early synthetic

\footnotetext{
*Correspondence: eric.hagan@canada.ca

Canadian Conservation Institute, 1030 Innes Road, Ottawa, ON K1B 4S7, Canada
}

dyes are generally categorised according to chemical structure. The most abundant synthetic dyes belong to the azo class. However, other chemical classes, including triphenylmethane, azine, xanthene, nitro, oxazine, indigoid and anthraquinone have each in turn had an important impact on the industry. As colourants were introduced to the market, many were used to colour materials other than textiles: e.g. waxes and varnishes, writing and printing inks, paint pigments, and early plastics. As a result, large quantities of synthetic colourants are present throughout museum collections around the world. Detailed reviews of the early industry [2, 3, 5-9] and respective dye chemistry [10-14] are plentiful in the

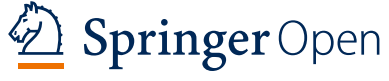

(c) Her Majesty the Queen in Right of Canada as represented by Canadian Conservation Institute 2021. This article is licensed under a Creative Commons Attribution 4.0 International License, which permits use, sharing, adaptation, distribution and reproduction in any medium or format, as long as you give appropriate credit to the original author(s) and the source, provide a link to the Creative Commons licence, and indicate if changes were made. The images or other third party material in this article are included in the article's Creative Commons licence, unless indicated otherwise in a credit line to the material. If material is not included in the article's Creative Commons licence and your intended use is not permitted by statutory regulation or exceeds the permitted use, you will need to obtain permission directly from the copyright holder. To view a copy of this licence, visit http://creativecommons.org/licenses/by/4.0/.The Creative Commons Public Domain Dedication waiver (http://creat ivecommons.org/publicdomain/zero/1.0// applies to the data made available in this article, unless otherwise stated in a credit line to the data. 
literature, and provide valuable context for current studies of heritage materials.

For many heritage objects, efforts are made to identify colourant materials for historical study, authentication and dating, and fastness evaluation. The large number of possible compounds makes it an overwhelming task to characterise them all, and in many cases reference materials are scarce. Analysis of these colourants is further complicated by the varied nomenclature used by manufacturers, where similar names were used for different dyes. The confusing letter codes (markings) after dye names, practice of mixing products, and mischaracterization of the product composition create additional layers of complexity. Norton [15] offers insight into some aspects of this confusing issue in a section titled "The Marks of Coal-Tar Colors". As just one example of the complexity, Norton indicated that $300,000 \mathrm{lb}$ of a dye named Cotton Black with various markings (unclassified by Schultz \#) was imported into the United States in 1914. The first edition of the Colour Index (CI) contains several listings that relate to this product name [16]: Cotton Black from Wülfing, Dahl \& Co. (CI\# 994); Cotton Black B, 3B, BG BGN BGNX, BN, C from BASF (azo direct dyes with no CI\#); Cotton Black $E$ extra from BASF (CI\# 581); Cotton Black G, 2G, 3G, PF extra, R, RN from BASF (azo direct dyes with no CI\#); and Cotton Black RW extra from BASF (CI\# 582). In some cases, a classified dye may also have a spectrum of possible compositions depending on the production method. An example is given by Crace-Calvert [17] when discussing the methyl and ethyl-rosanilines, and the production of various forms of Hofmann's Violet:

...by varying the circumstances of experiment, instead of three of the hydrogen being replaced by ethyl, dyes may be obtained having two, or only one, replaced by ethyl; moreover, by substituting methyl iodide for ethyl iodide, corresponding methyl compounds may be prepared. In this way Hofmann violets are obtained of different shades, varying from $R R R$, the very red, which is principally a salt of monomethylated rosaniline $\mathrm{C}_{28} \mathrm{H}_{18}\left(\mathrm{CH}_{3}\right) \mathrm{N}_{3}$, to $\mathrm{BBB}$, the bluest shade.

In the 1980s, Schweppe $[18,19]$ aimed to simplify the problem by providing a shortlist of 65 early synthetic organic dyes with notes to assist with their identification, while also highlighting a subset of 22 stated as the most common [20]. In the field of heritage science, this list has become a common reference despite the ambiguous selection criteria. In a review of the early synthetic dyes, Barnett [20] remarks that areas for further work include identifying the most common materials using 19th century trade literature, and compiling respective fastness data. The challenge, of course, is finding quantitative data regarding dye production or use. The Colour Index is an encyclopaedic resource of colourant data; however, information related to the degree of use is limited, and modern lightfastness data is unavailable for many of the earliest materials. Similarly, most trade books of the period simply outline the vast range of products available. It is likely that a significant number of the catalogued products were rarely used, and analysis could be prioritized to specific materials given the appropriate information.

This study investigates several trends in the synthetic dye industry using early 20th century literature: multiple editions of the CI [16, 21, 22], Norton's census [15], and the annual Census of Dyes and Coal Tar Chemicals from the US Tariff Commission [23, 24]. The goal of the work is to provide a framework to better understand the most prominent early synthetic dyes, optimise methods for identification, and further develop lightfastness data for risk assessment tools. Findings are presented as summary statistics due to the large number of materials, while tabulated values are provided in a complementary dataset for further research work [25].

\section{Data mining the colour index}

Many reference texts were published with lists of dyes during the latter half of the 19th century, leading to the development of different classification systems [26]. The first widely adopted approach was Tabellarische übersicht der Künstlichen Organischen Farbstoffe by Schultz and Julius [27], which was published in seven editions between 1888 and 1931. The fifth edition [28], retitled Farbstofftabellen, became a template for the first edition of the CI and resulted in a legal dispute between the two groups [26]. The CI employed a new numbering system, and provided a convenient table for cross-referencing with listings in Farbstofftabellen. The table is a valuable resource since it allows conversion from the 1914 Schultz number to the first CI number [16], and subsequently to the CI constitution number in current use [21]. This conversion was applied in the following section during a review of census data, where US dye imports and production quantities were published with the 1914 Schultz number prior to 1924.

The CI contains a large amount of information showing interesting trends when extracted and studied as a dataset. For example, a column of citations for each dye provides the approximate date of introduction for each compound. Using this information, the earliest date was tabulated for each dye, and a sorted list was used to generate a plot of cumulative dyes invented through time. The result in Fig. 1 shows a sigmoid curve with features characteristic of the stages of an evolving technology: 


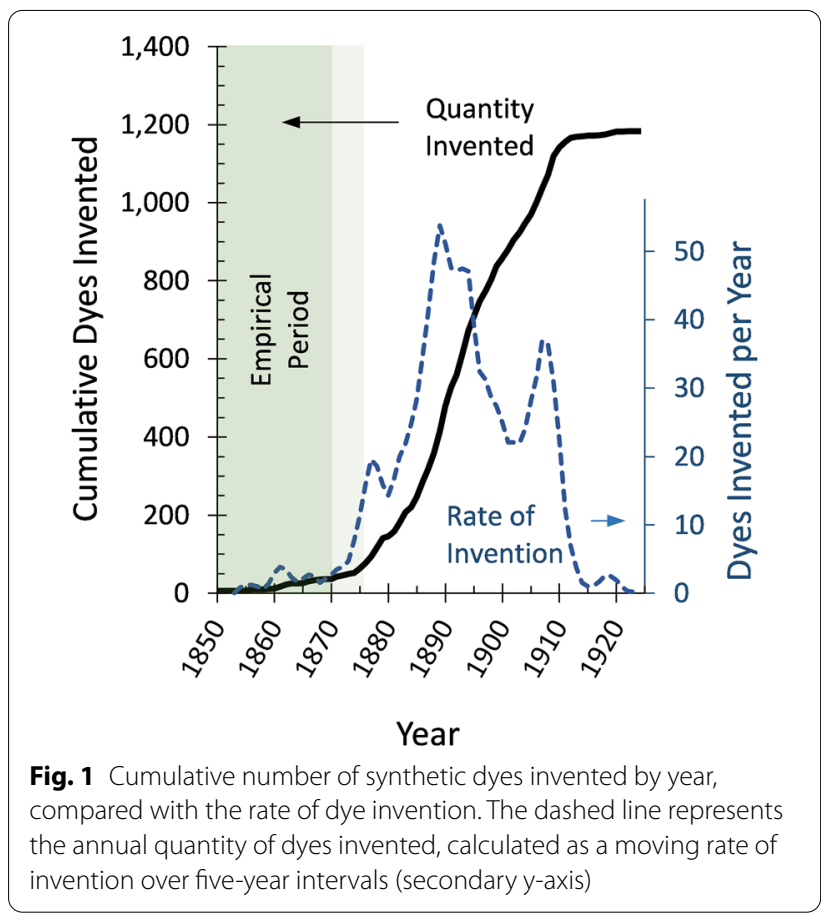

birth, development, maturity and stagnation. At a conference celebrating the centennial of Perkin's creation of mauveine, Lecher [5] described the stage up to $\sim 1870$ as the 'empirical period' when the structural theory was not yet established. This was followed by the 'rational period', as the Kekule structure of benzene was developed in 1865 [29] and later accepted. When the industry entered this latter period, the introduction of new dyes accelerated as specific organic compounds were sought after. This is evident in Fig. 1, where the rate of dye introduction accelerates shortly after 1870 , and peaks around 1889 . Another moment of significance is observed at the year 1893, when $50 \%$ of this first wave of dyes was introduced.

Further information is added to this overview of the early synthetic dye industry by cross-referencing date of introduction with chemical classification. The stacked histogram in Fig. 2 highlights the distribution of dyes invented over time by chemical class, with a dominant peak generated by the azos around 1890 (cf. Fig. 1). A smaller peak at 1907 is due to the development of anthraquinone and sulphur dyes, which is followed by a cluster of indigoids around 1915. The introduction of triphenylmethane and xanthene dyes is scattered throughout the time period, along with the remainder of chemical classes grouped as 'other' to simplify the plot.

The CI provides occasional qualitative indications of popularity in the descriptive text for the listed dyes, but the information is sparse and of limited use. Another potential popularity indicator is the number of

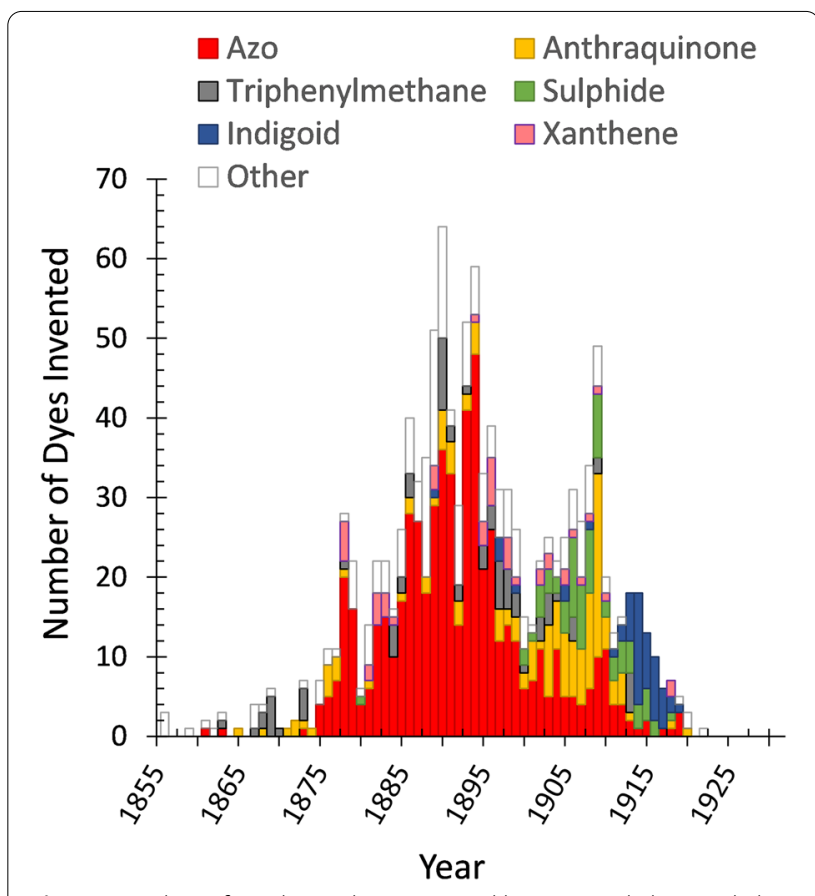

Fig. 2 Number of synthetic dyes invented by year and chemical class

manufacturers, $M$, that offered each product. One would assume that compounds having many manufacturers would also experience significant commercial use. Those with one manufacturer may have had patent protection; however, this was likely circumvented or ignored using different methods of manufacture and varied rules by country. Gardener [30] provides a compilation of articles related to the British coal-tar industry, with the issue of patent protection highlighted throughout the text. In one paper, Bloxam [31] states "The whole of organic chemistry has been wondrously advanced by the desire of the maker of dyestuffs on the one hand to obtain monopolies of new colours, and on the other hand to avoid paying royalties under existing patents". To illustrate the varied number of manufacturers, Fig. 3 shows a plot of the number of dyes having more than a given value of $M-$ defined here as the manufacturers in exceedance, $M_{e}$. The plot was constructed in this manner to quickly determine how many colourants would be required for future analysis (e.g. chemical and lightfastness) if we target those with more than some threshold number of manufacturers. Nearly all dyes had one or more manufacturers, while less than $50 \%$ had $M \geq 3$, and only $10 \%$ are indicated with $M \geq 15$. The number of manufacturers is also used in the following section when plotting import and production quantities from US census data.

A final parameter investigated in the $\mathrm{CI}$ was the lightfastness rating for each colourant. The third edition [22] was reviewed for ISO and AATCC lightfastness values 


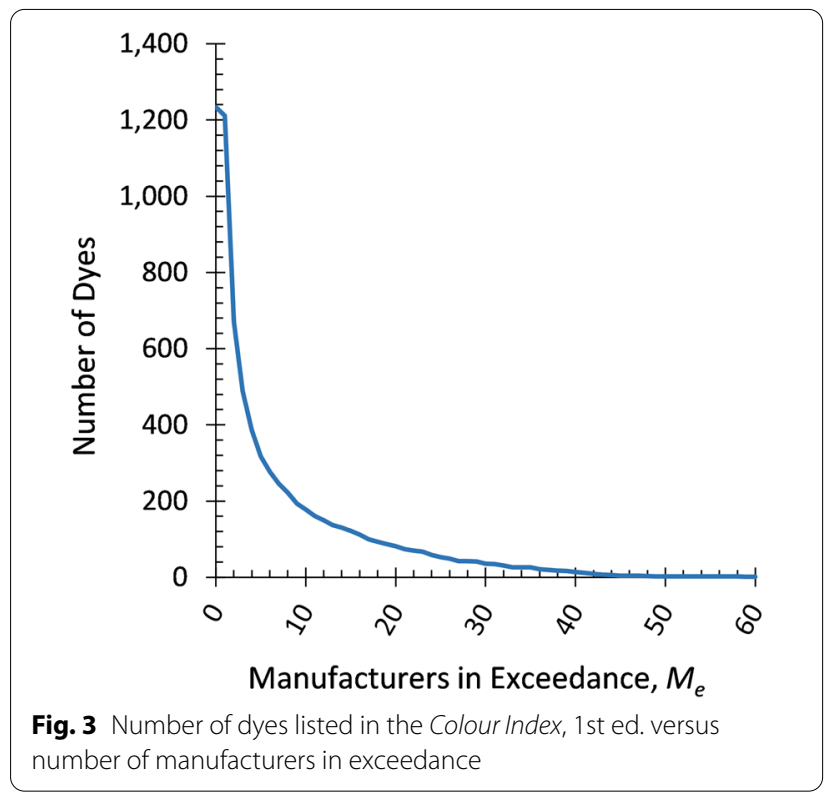

related to each of the 1,230 synthetic organic dyes listed in the first edition [16], using a conversion table in the second edition [21] for the two CI numbering systems. In total, 432 were found, or $\sim 35 \%$ of the total list. Counts of dyes with half-step ratings (e.g. ISO 2-3) were split equally into adjacent bins of full step ISO values to plot a histogram of the quantity of dyes with each lightfastness. Figure 4 shows the resulting percentage of dyes having each ISO value, with a peak at ISO 3 . This distribution is affected by the number of dyes with ISO ratings listed in the CI, which varies significantly by chemical class and application type. The distributions are also highlighted separately for the direct and vat dyes, showing peaks at the lower and higher ISO ratings respectively. Figure 5 gives a related plot in which the relationship between the ISO and AATCC lightfastness scales is evaluated using data from 237 of the dyes, where both measures were available.

Many of the earliest synthetic dyes were highly fugitive to light, which is well documented in literature of the period [32]. When Lauth discussed a new dye (Violet de Paris) in 1867 , he gave some perspective on the shifting public opinion toward lightfastness:

The violets obtained from methyl-aniline possess a richness and purity which leave nothing to be desired ... Nevertheless they were not adopted by manufacturers, who, indeed at the time above mentioned (1861), attached less importance to the beauty of a colour than to its permanence. In this latter respect the methyl-aniline violets do not excel, and consequently dyers would have nothing to do with them. Gradually, however, people have become

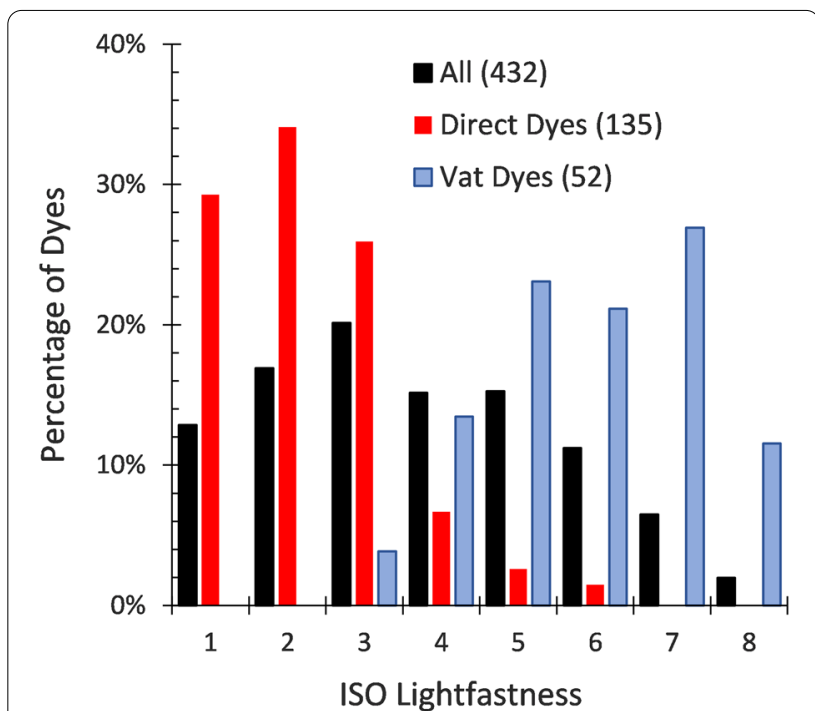

Fig. 4 ISO lightfastness ratings in the third edition of the Colour Index [22], for colourants listed in the first edition [16]. Data selected for normal depth of shade, and direct dyeing without aftertreatment where applicable. ISO values for mordant dyes primarily relate to wool with chrome mordant. A small number of duplicates with the same $\mathrm{Cl}$ generic name was removed for this plot

accustomed to colours which fade on exposure to the solar rays. Indeed the public taste at the present day, in colours as in everything else, inclines rather to tinsel than to solid excellence.

In his 1896 Hofmann memorial lecture, Perkin [6] also points to the shift of public interest toward new

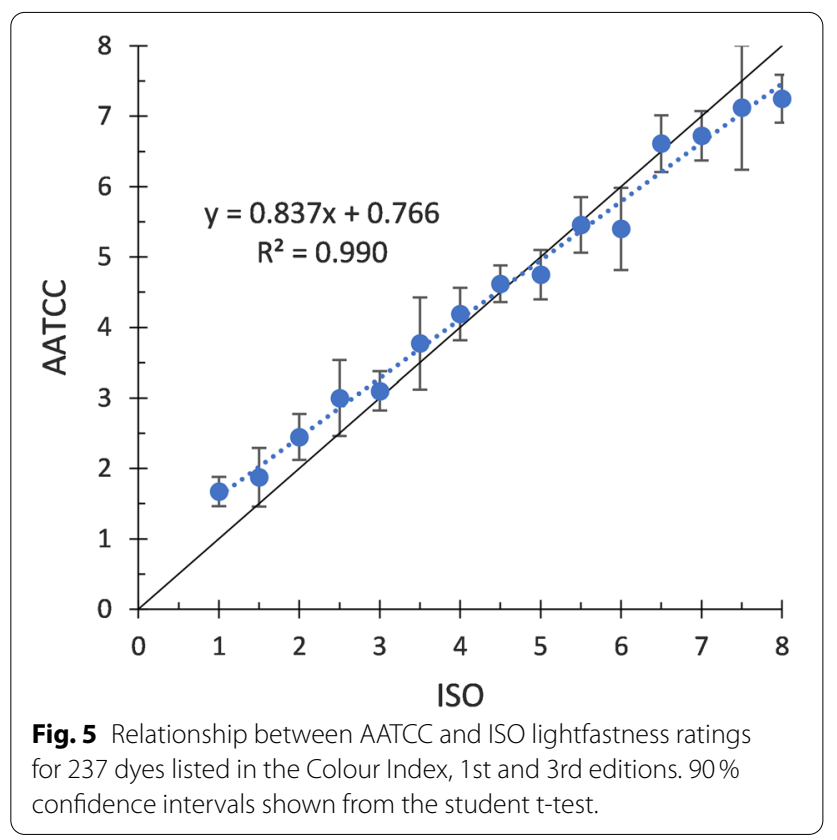


vibrant colours at the expense of fastness. In a later review of the industry, Whittaker [33] comments on the unfortunate discovery of so many fugitive dyes during the early development of the industry:

"The basic dyes supply the next series of milestones. I have always felt that it was a tragedy that these dyes, of still unsurpassed brilliant hues coupled with extreme fugitiveness, were discovered so early in the development of synthetic dyes. Their lack of fastness retarded the use of the then so-called "Anilines" for years, and provided the old-time dyers with a strong justification for their hostility and conservatism. The other misfortune was that these brilliant hues found their way into the textile designers' studios, and were repeatedly sent to the dyers for reproduction in a fastness for which there were no comparable dyes. For example, Malachite Green was discovered in 1878, but the dyer had to wait until 1920 for Caledon Jade Green, which first enabled him to give with confidence a Jade Green hue suitable for soft furnishings and washing fabrics. Meantime dyers were compelled to write thousands of letters regretting inability to dye the hues requested. The leading basic dyes appeared in the following sequenceMagenta (1858), Methyl Violet (1866), Methylene Blue (1876), Malachite Green (1878), Auramine 0 (1883), whilst Rhodamine B followed in 1887 and Rhodamine 6G in 1892."

When reviewing the extensive list of materials in the first edition of the $\mathrm{CI}$, it is natural to wonder which materials were used in significant quantities, and most likely prevalent in museum collections. The CI was developed as a catalogue of all colourants, but only provides occasional information about popularity using qualitative terms such as 'used extensively for...". It is possible that many of the colourants were never used in significant quantities, while others achieved varying degrees of popularity. Some colourants are known to have had a period of success prior to their replacement by a new dye with improved properties and/or simplified production methods. An example is found in the history of the earliest synthetic green dyes. Cherpin created the first of value called aldehyde green in 1862, which was later displaced by Perkins green, iodine green, and methyl green. The CI notes the prior popularity for many of these dyes, as well as their replacement and ultimate obsolescence. Although limited quantitative data exists regarding the use of earliest synthetic dyes, valuable information is available from United States census data starting in 1913-1914. The following section provides an overview of data collected from government documents of the period.

\section{US imports and domestic production}

A resource for assessing general dye popularity is the US census data published in the early 20th century, at a time when there was significant pressure to boost domestic production and compete with manufacturers in Europe. The outbreak of World War I in July 1914 led to a severe disruption of the dye industry due to the broad reliance on supplies from Germany. This included finished products, as well as the large number of intermediates for dye manufacture. The issue was often described as the 'dyestuff famine' or 'dyestuff crisis' [34, 35], and short-lived attempts were made to return to traditional methods using natural dyes [36] with limited success. Commenting on the state of the US dye industry, Hesse [34] made the following observations in November 1914:

At or about the end of 1912, 76 different chemical dyes were made in this country; today 100 such are made - in two years a 33 per cent increase; the United States market probably has no fewer than 900 different chemical dyes, each of them in active use, some of them to a very small extent, others to a very large extent and, no doubt, many of each of these could be eliminated and their places taken by others now on the market.

At approximately the same time, the mystery regarding US dye imports was addressed by a commercial agent named Thomas H. Norton at the US Department of Commerce (Fig. 6). With careful planning to avoid the pitfalls experienced by similar efforts in Britain, Norton successfully conducted a census of imports for the 1913-1914 fiscal year [15]. His report included a large table of import quantities above 10,000 lb. (4536 $\mathrm{kg}$ ), dollar values, commercial dye name, and Schultz number where available. These quantities were evaluated in the present study by converting the Schultz numbers to those of the first CI edition. Figure $7 \mathrm{a}$ shows the quantities reported by Norton versus CI number, with markers at the top indicating many of the chemical classes. The top-ten imported dyes are noted with labels on the peaks, and outlined in Table 1. Further information is provided in Appendix: Table 2, and the accompanying dataset [25]. Norton also catalogued dyes without a Schultz number; however, these only amounted to $\sim 16 \%$ of the total import quantity (see 


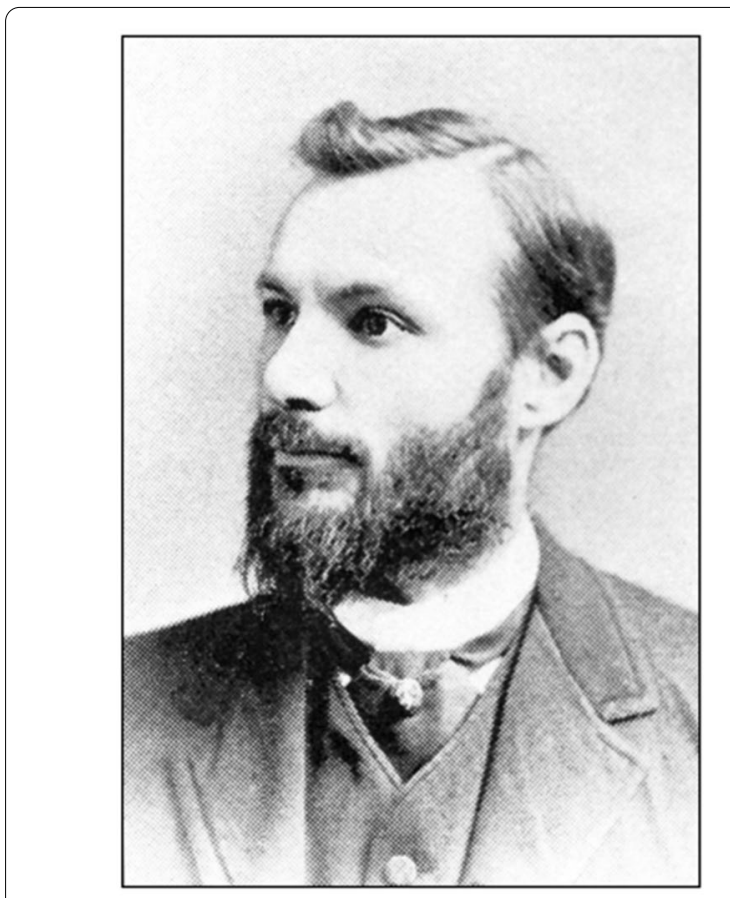

Fig. 6 Thomas H. Norton (1851-1941). Source: Oesper Collections in the History of Chemistry, University of Cincinnati [37]. Used with permission

Appendix: Table 3 for those above 100,000 lb). The results of Fig. 7a provide a useful indication of which dyes were predominantly used in the US when domestic manufacturing was still maturing.

A related development from Norton's census was the US Revenue Act of 1916. This led to the formation of the Tariff Commission, and enacted measures to temporarily support the US dyestuff industry through trade policy. As a means of tracking progress, an annual report was published by the Tariff Commission starting in 1918 (with 1917 data) called the Census of Dyes and Coal-Tar Chemicals. The report continued for several decades, with each issue summarising quantitative data regarding dye production and imports by chemical classification number (i.e. Schultz prior to 1924, followed by early CI\#). For the current study, a review of these data was undertaken by tabulating production amounts from 1917 through the 1920's. Conversion to first edition CI number also allowed cross-referencing with data summarised in the previous section. Figure $7 \mathrm{~b}$ and $\mathrm{c}$ show imports and domestic production data respectively for 1920, where the log-scale highlights the large quantities of some dyes. Unlike Norton's census, subsequent publications list amounts below 10,000 lb (not shown here); however, some domestic production data was withheld to maintain manufacturer privacy. A small group, particularly sulphur dyes, included production amounts but were not characterised by Schultz number.

Figure 8a presents US imports for the 1914 fiscal year versus the number of manufacturers listed in the first edition of the $\mathrm{CI}$ for the respective dyes. A similar plot is given in Fig. 8b, showing peak annual production for the period of 1917-1924 versus number of manufacturers. There is significant scatter in these data; however, the plots indicate a trend of increasing dye quantities with number of manufacturers. In both plots, data points circled in red indicate one of the 65 dyes in the Schweppe list [18]. Bracketed numbers in the legends give the number of points plotted for each series. For example, Fig. 8a shows 259 materials imported into the US in quantities greater than $10,000 \mathrm{lb}$, of which 43 are described by Schweppe. Dyes imported in large quantities, and not in Schweppe's list, may be worth further examination if the CI describes applications relevant to heritage objects.

Disruption to the dye industry during WWI contributed to the United States domestically producing many of the dyes that were previously imported in significant quantities. Figure 9 explores this trend with a plot of the production and imports of dyes in the United States during 1920 versus 1914 imports (Norton's census) for the corresponding materials. By 1920, approximately one third were produced in the US in quantities significantly larger than the prior 1914 imports. Some continued to be imported ( $41 \%$ ); however, these were typically at much lower quantities. A small number (6\%) were both imported and produced in the US during 1920, with production dominant.

A broader assessment of census data from 1917 through the 1920's suggests that less than one quarter of the colourants in the CI were produced or imported in the United States in significant quantities during the period. In comparison, Norton's census listed 259 colours with Schultz number imported in quantities above $10,000 \mathrm{lb}(\sim 21 \%$ of the CI) during the 1913-1914 fiscal year. Adding the list of domestic products (tabulated by Norton without quantities), and removing duplicates, gave 289 compounds with unique Schultz number that were imported and/or produced in the US. There were also several imports of unknown composition in Norton's census: 96 azo, 23 sulphur, and 68 unclassified. This likely included duplicate counts of similar compounds. See Appendix: Table 3 for the small subset of undefined dyes imported in amounts over $100,000 \mathrm{lb}$. The overall findings emphasize that a subset of the CI list is worth greater attention for further analysis. It is also important to note that some applications of concern to heritage collections may have used colourants in relatively small amounts that are overshadowed by these general statistics. 

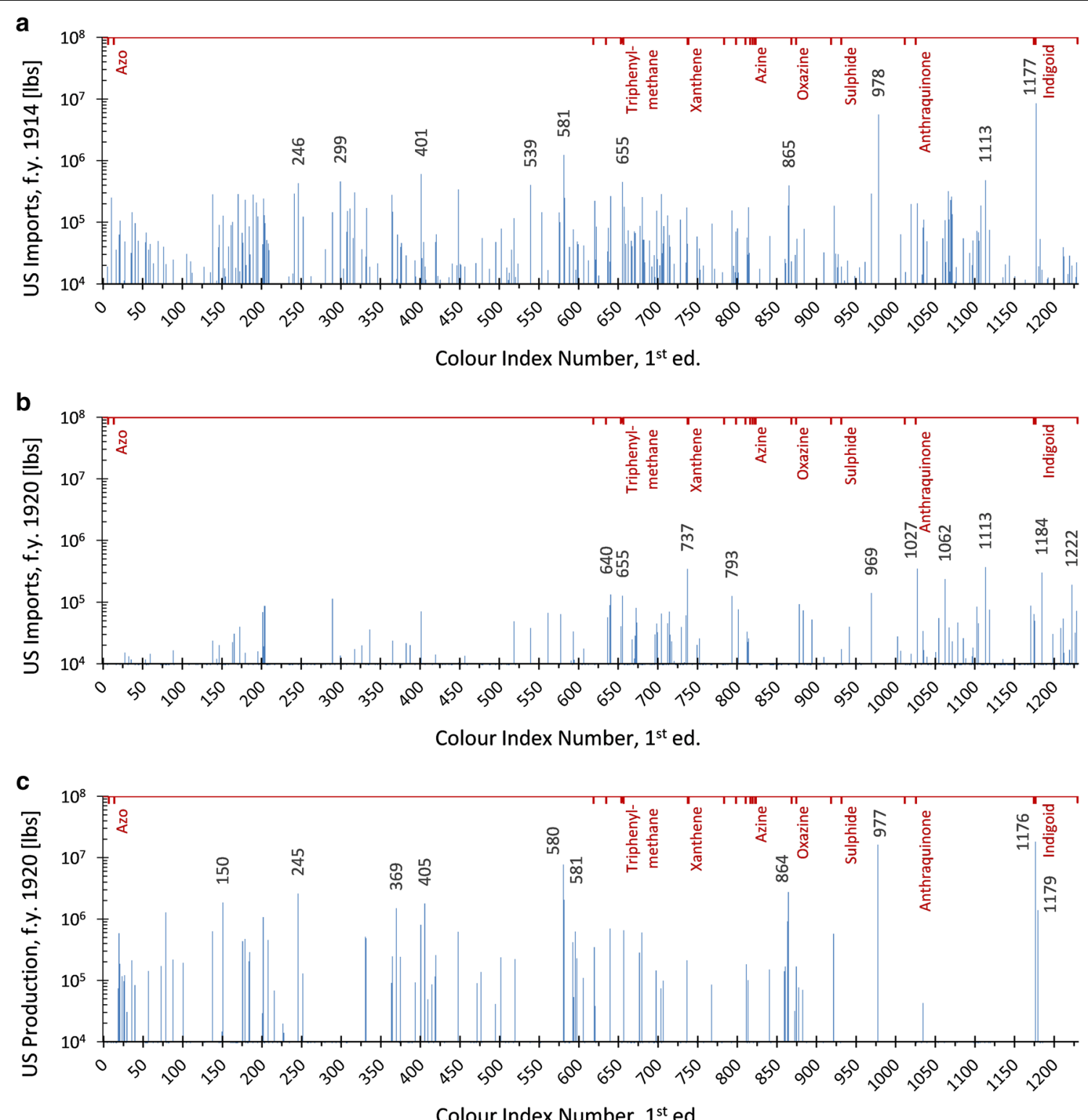

Fig. 7 Quantity of dyes imported or produced in the United States versus 1st ed. Colour Index number: a 1914 imports from Norton's census; b 1920 imports; c 1920 production. Labels shown for the 10 largest values. See Appendix for descriptions of the labelled dyes

\section{Conclusions}

Statistics of the early synthetic dye industry were reviewed by extracting colourant data from the CI including date of introduction, number of manufacturers, chemical class, and lightfastness. These parameters were plotted to show trends with respect to the number of dyes introduced over time, the rate of introduction, and the types of colourants from the mid19th century to 1924. The number of manufacturers was shown as a potential indicator of popularity with values ranging from zero to more than 60 per colourant. Lightfastness data with ISO and AATCC ratings were summarised by cross-referencing between multiple editions of the CI. This was used to highlight the relationship between ISO and AATCC rating systems, and also the distribution of ISO lightfastness for 432 colourants listed in the 1st edition of the CI.

The analysis of CI data was followed by a review of United States census literature from 1914 through the 1920 's. In broad terms, census data suggested that less 
Table 1 Top ten dyes imported into the United States in 1914

\begin{tabular}{|c|c|c|c|c|c|c|c|c|}
\hline Rank & $\begin{array}{l}\text { Schultz \# } \\
1914\end{array}$ & $\begin{array}{l}\mathrm{Cl} \# \\
1 \text { st ed. }\end{array}$ & $\begin{array}{l}\mathrm{Cl} \# \\
\text { 2nd ed. }\end{array}$ & Generic Name & Class & $\begin{array}{l}\text { Date } \\
\text { Intro. }\end{array}$ & M & $\begin{array}{l}\text { Imports } \\
\mathrm{Ib} \times 10^{3}\end{array}$ \\
\hline 1 & 874 & 1177 & 73,000 & Vat Blue 1 & Indigoid & 1890 & 13 & 8507 \\
\hline 2 & 720 & 978 & 53,185 & Sulphur Black 1 & Sulphur & 1896 & 23 & 5615 \\
\hline 3 & 462 & 581 & 30,235 & Direct Black 38 & Trisazo & 1901 & 39 & 1238 \\
\hline 4 & 333 & 401 & 22,590 & Direct Blue 2 & Disazo & 1890 & 32 & 606 \\
\hline 5 & 842 & 1113 & 69,825 & Vat Blue 6 & Anthraquinone Vat & 1903 & 6 & 479 \\
\hline 6 & 275 & 299 & $\begin{array}{l}26,695 \text { see also } \\
26,750 ; 26,751\end{array}$ & Mordant Black 5 & Disazo & 1889 & 24 & 460 \\
\hline 7 & 493 & 655 & 41,$000 ; 41000 B$ & $\begin{array}{l}\text { Basic Yellow 2; } \\
\text { Solvent Yellow } 34\end{array}$ & Ketonimine & 1883 & 18 & 449 \\
\hline 8 & 217 & 246 & 20,470 & Acid Black 1 & Disazo & 1891 & 42 & 429 \\
\hline 9 & 436 & 539 & 31,560 & Direct Black 9 & Trisazo & 1896 & 14 & 403 \\
\hline 10 & 700 & 865 & 50,420 & Acid Black 2 & Azine & 1867 & 41 & 395 \\
\hline
\end{tabular}

Schultz \# (1914) is shown from source data, along with the conversions to first and second edition Cl numbers. Approximate date of introduction and number of manufacturers are given from the 1 st ed. of the $\mathrm{Cl}$
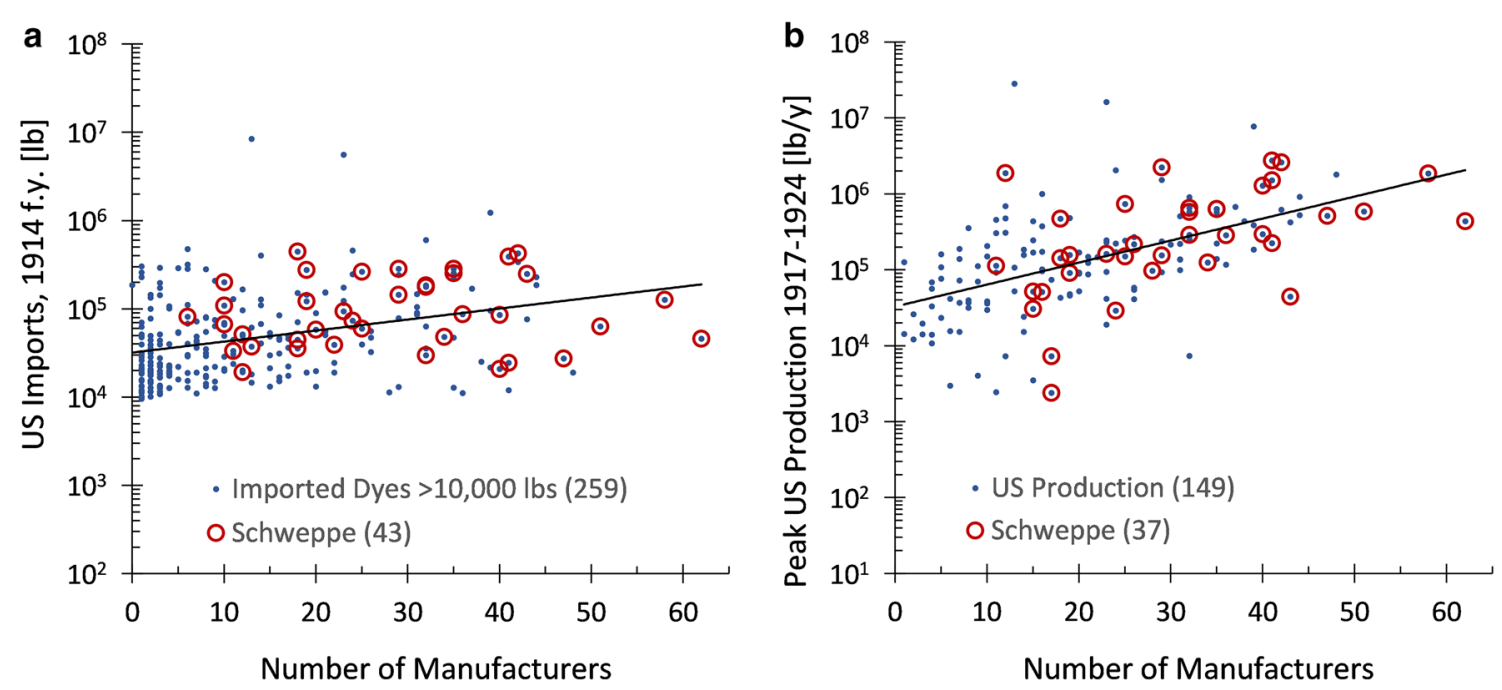

Fig. 8 Imports and production of dyes in the United States versus the number of manufacturers listed in the Colour Index for each colourant: a imports during the 1914 fiscal year; b peak annual production reported during the period of 1917-1924

than a quarter of the colourants listed in the 1st edition of the CI were imported or produced in the US in significant amounts. Norton's earlier census for 1913-1914 listed 259 colours with Schultz number imported to the US in quantities above $10,000 \mathrm{lb}(\sim 21 \%$ of the $\mathrm{CI})$, and a total of 289 classified (Schultz \#) compounds imported and/or produced. There were also several compounds of unknown composition in Norton's census that made up 16\% of total imports: 96 azo, 23 sulphur, and 68 unclassified. Census data were further used to show the amounts of each colourant imported and produced in the US, which was then compared with the number of manufacturers. Comparisons were also made with the Schweppe list of synthetic dyes since it is frequently used as a reference for dye analysis. Several of the dyes on Schweppe's list were imported or produced in significant quantities during the studied time period; however, the results highlight that many other products deserve further consideration. 


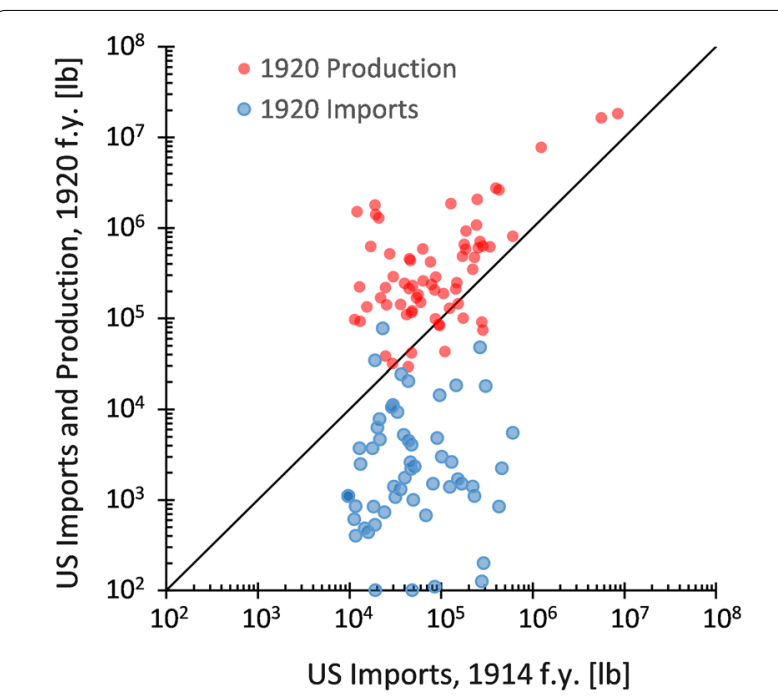

Fig. 9 Comparison of US imports of dyes in 1914 with domestic production and imports for the same dyes in 1920

To support research related to the history and preservation of heritage collections, a compilation of the tabulated values is provided as an open dataset [25]. In our ongoing work, this information provides a tool for selecting specific samples of interest for chemical analysis and lightfastness testing using a set of criteria: introduced 1870 and earlier (empirical period); produced or imported in large quantities $(\geq 100,000 \mathrm{lb} / \mathrm{yr})$; having a large number of manufacturers listed in the CI $(M \geq 15)$; or historically significant. Appendix: Table 2 provides a summary of colourants meeting these criteria, while the dataset [25] allows anyone to generate a custom list based on parameters of interest.

In parallel to the work described here, a list of available period samples was tabulated from trade books and dying texts (i.e. commercial name, and manufacturer where available). This was cross-referenced with the first edition of the Colour Index to verify the CI\# where possible, and then pick the target samples of interest for analysis. At the present time, over 100 samples have been studied for the effects of light exposure with a custom fadometer, and chemical markers using gas chromatography-mass spectrometry (GC-MS). The goal is to provide an open database for researchers to explore the results, and build upon in future work. Finally, the samples with and without light damage are catalogued and stored for possible analysis with other analytical techniques.

\section{Appendix}

Table 2 gives a summary of dyes in the first edition of the $\mathrm{CI}$ [16] that meet one or more of the following criteria: (a) introduced 1870 or earlier; (b) imported or produced in quantities of 100,000 lb/yr or more (1914-1924); (c) having 15 or more manufacturers listed in the CI. Matches for each criterion are emphasised in bold and underlined for clarity. A question mark in the column of peak annual US production (1917-1924) indicates that the dye was produced in at least one reporting period; however, the quantity was withheld for manufacturer privacy. This list of dyes is also supplemented with some materials of known relevance or historical significance that are not already captured: e.g. the first sulphur dye (CI 933), and early dyes without CI number (aldehyde green, aldehyde blue). Additionally, cross-referencing with the Schweppe list [18] of important early synthetic dyes showed a near match for Mordant Red 3 (CI 1034): introduced 1871, with nearly $82,000 \mathrm{lb}$ imported to the US in 1914 . The dye was added to the table in consideration of these factors. 
Table 2 List of dyes fulfilling selection criteria based on date of introduction ( $\leq 1870)$, number of manufacturers ( $\geq 15)$, US imports and production ( $\geq 100,000 \mathrm{lb} / \mathrm{yr})$, or other significance

\begin{tabular}{|c|c|c|c|c|c|c|c|c|c|}
\hline 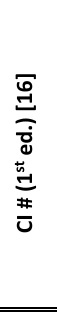 & 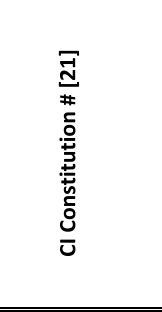 & 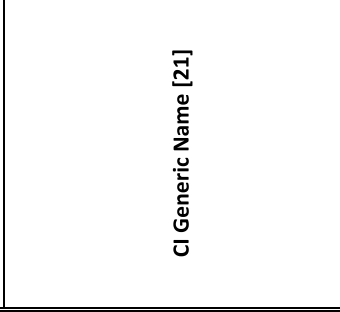 & 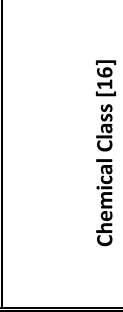 & 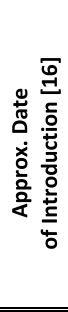 & 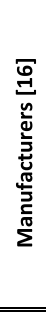 & 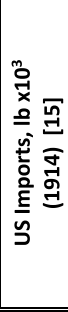 & 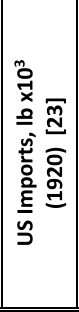 & 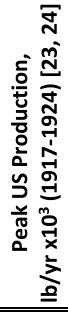 & 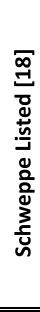 \\
\hline 2 & 10005 & Mordant Green 4 & Nitroso & 1875 & $\underline{17}$ & - & - & - & $\mathrm{N}$ \\
\hline 5 & 10020 & Acid Green 1 & Nitroso & 1885 & $\underline{19}$ & 19.1 & 0.500 & 45.9 & $\mathrm{~N}$ \\
\hline 7 & 10305 & & Nitro & $\underline{1849}$ & 12 & - & - & - & $Y$ \\
\hline 8 & 10310 & & Nitro & $\underline{1869}$ & 1 & - & - & - & $\mathrm{N}$ \\
\hline 9 & 10315 & Acid Yellow 24 & Nitro & $\underline{1856}$ & $\underline{24}$ & - & - & - & $Y$ \\
\hline 10 & 10316 & Acid Yellow 1; Food Yellow 1 & Nitro & 1879 & $\underline{43}$ & $\underline{250}$ & - & 44.5 & $\mathrm{Y}$ \\
\hline 15 & 11000 & Solvent Yellow 1 & Monoazo & $\underline{1861}$ & $\underline{20}$ & - & - & 52.3 & $\mathrm{~N}$ \\
\hline 16 & 13015 & Acid Yellow 9 & Monoazo & 1877 & $\underline{32}$ & 36.0 & 8.38 & 7.3 & $\mathrm{~N}$ \\
\hline 17 & $11160 ; 37210$ & $\begin{array}{l}\text { Solvent Yellow 3; Azoic Diazo } \\
\text { Component } 4\end{array}$ & Monoazo & 1877 & $\underline{19}$ & - & - & 48.1 & N \\
\hline 19 & 11020 & Solvent Yellow 2 & Monoazo & 1876 & $\underline{16}$ & - & - & $\underline{101}$ & $\mathrm{~N}$ \\
\hline 20 & $11270 ; 11270 \mathrm{~B}$ & Basic Orange 2; Solvent Orange 3 & Monoazo & 1875 & $\underline{51}$ & 63.3 & - & $\underline{586}$ & $Y$ \\
\hline 21 & $11320 ; 11320 \mathrm{~B}$ & Basic Orange 1; Solvent Orange 4 & Monoazo & 1877 & $\underline{31}$ & $\underline{106}$ & 3.31 & $\underline{221}$ & $\mathrm{~N}$ \\
\hline 23 & 11920 & Solvent Orange 1 & Monoazo & 1875 & $\underline{20}$ & - & - & $?$ & $\mathrm{~N}$ \\
\hline 24 & 12055 & Solvent Yellow 14 & Monoazo & 1883 & $\underline{36}$ & - & - & $\underline{117}$ & $\mathrm{~N}$ \\
\hline 26 & 15970 & Acid Orange 12 & Monoazo & 1878 & $\underline{28}$ & 11.4 & - & 96.6 & $Y$ \\
\hline 27 & 16230 & Acid Orange 10; Food Orange 4 & Monoazo & 1878 & $\underline{34}$ & 48.5 & 15.3 & $\underline{124}$ & $Y$ \\
\hline 28 & 16100 & Acid Orange 14 & Monoazo & 1878 & $\underline{19}$ & - & - & $?$ & $\mathrm{Y}$ \\
\hline 30 & 17200 & Acid Red 33; Food Red 12 & Monoazo & 1890 & $\underline{15}$ & - & - & 30.7 & $Y$ \\
\hline 31 & 18050 & Acid Red 1 & Monoazo & 1902 & $\underline{26}$ & - & 7.03 & $\underline{218}$ & $Y$ \\
\hline 36 & 14025 & Mordant Yellow 1 & Monoazo & 1887 & $\underline{29}$ & $\underline{145}$ & - & $\underline{2233}$ & $Y$ \\
\hline 40 & 14030 & & Monoazo & 1885 & $\underline{39}$ & 96.5 & 1.20 & $\underline{386}$ & $\mathrm{~N}$ \\
\hline 53 & 16580 & Acid Violet 3 & Monoazo & 1891 & $\underline{16}$ & 47.1 & 11.8 & $\underline{173}$ & $\mathrm{~N}$ \\
\hline 56 & 16600 & Acid Violet 6 & Monoazo & 1890 & 5 & - & - & $\underline{108}$ & $\mathrm{~N}$ \\
\hline 57 & 18055 & Acid Violet 7 & Monoazo & 1902 & $\underline{18}$ & 36.0 & 0.100 & $\underline{143}$ & $Y$ \\
\hline 63 & $16010 ; 16011$ & Acid Orange 16 & Monoazo & 1879 & $\underline{15}$ & 21.5 & - & $?$ & $\mathrm{~N}$ \\
\hline 69 & 12120 & Pigment Red 3 & Monoazo & 1905 & $\underline{17}$ & 49.7 & - & $?$ & $\mathrm{~N}$ \\
\hline 73 & 12140 & Solvent Orange 7 & Monoazo & 1883 & $\underline{24}$ & - & 2.21 & $\underline{171}$ & $\mathrm{~N}$ \\
\hline 78 & 16020 & Acid Orange 17 & Monoazo & 1879 & $\underline{23}$ & - & 0.500 & 18.9 & $\mathrm{~N}$ \\
\hline 79 & 16150 & Acid Red 26 & Monoazo & 1878 & $\underline{40}$ & 21.0 & 1.92 & $\underline{1285}$ & $\mathrm{Y}$ \\
\hline 81 & 12020 & Solvent Brown 5 & Monoazo & 1878 & $\underline{18}$ & - & - & $?$ & $\mathrm{~N}$ \\
\hline 82 & 12170 & Solvent Red 4; Pigment Red 40 & Monoazo & $?$ & $\underline{20}$ & - & 0.500 & $?$ & $\mathrm{~N}$ \\
\hline 88 & 16180 & Acid Red 17 & Monoazo & 1878 & $\underline{41}$ & 24.7 & 16.5 & $\underline{224}$ & $Y$ \\
\hline 89 & 16250 & Acid Red 44 & Monoazo & 1883 & $\underline{16}$ & - & 0.331 & - & $\mathrm{Y}$ \\
\hline 101 & $\begin{array}{c}\text { see } 11290, \\
11300,11335\end{array}$ & & Monoazo & 1898 & 12 & - & - & $\underline{474}$ & $\mathrm{~N}$ \\
\hline 135 & 12210 & Basic Blue 16 & Monoazo & 1886 & $\underline{16}$ & 15.4 & 0.055 & $?$ & $\mathrm{~N}$ \\
\hline 138 & 13065 & Acid Yellow 36 & Monoazo & 1879 & $\underline{35}$ & $\underline{285}$ & 23.8 & $\underline{629}$ & $Y$ \\
\hline 142 & 13025 & Acid Orange 52 & Monoazo & 1875 & $\underline{15}$ & - & - & $?$ & $\mathrm{~N}$ \\
\hline 143 & 13080 & Acid Orange 5 & Monoazo & 1876 & $\underline{36}$ & 11.2 & 12.0 & $?$ & $Y$ \\
\hline 145 & 13090 & Acid Orange 1 & Monoazo & 1880 & $\underline{22}$ & 39.3 & 10.4 & - & $\mathrm{Y}$ \\
\hline 146 & 13096 & & Monoazo & 1880 & $\underline{31}$ & 90.5 & 20.1 & $\underline{138}$ & $\mathrm{~N}$ \\
\hline
\end{tabular}


Table 2 (continued)

\begin{tabular}{|c|c|c|c|c|c|c|c|c|c|}
\hline 148 & 14270 & Acid Orange 6 & Monoazo & 1875 & $\underline{28}$ & - & - & $?$ & $\mathrm{Y}$ \\
\hline 150 & 14600 & Acid Orange 20 & Monoazo & 1876 & $\underline{24}$ & - & 1.32 & 29.0 & $\mathrm{Y}$ \\
\hline 151 & 15510 & Acid Orange 7 & Monoazo & 1876 & $\underline{58}$ & $\underline{128}$ & 2.30 & $\underline{1850}$ & Y \\
\hline 161 & 15575 & Acid Orange 8 & Monoazo & 1887 & $\underline{20}$ & 90.2 & - & 88.8 & $\mathrm{~N}$ \\
\hline 163 & 15850 & Pigment Red 57 & Monoazo & 1903 & 4 & $\underline{101}$ & 22.6 & 68.4 & $\mathrm{~N}$ \\
\hline 165 & 15585 & Pigment Red 53 & Monoazo & 1902 & 5 & - & 30.8 & $\underline{161}$ & $\mathrm{~N}$ \\
\hline 170 & 16500 & Mordant Black 9 & Monoazo & 1902 & 6 & $\underline{285}$ & 2.80 & $?$ & $\mathrm{~N}$ \\
\hline 176 & 15620 & Acid Red 88 & Monoazo & 1877 & $\underline{62}$ & 46.4 & - & $\underline{434}$ & $\mathrm{Y}$ \\
\hline 179 & 14720 & Acid Red 14; Food Red 3 & Monoazo & 1883 & $\underline{44}$ & $\underline{231}$ & 15.1 & $\underline{527}$ & $\mathrm{~N}$ \\
\hline 180 & 14835 & Acid Red 12 & Monoazo & ? & 10 & 20.1 & - & $\underline{206}$ & $\mathrm{~N}$ \\
\hline 182 & 16045 & Acid Red 13 & Monoazo & 1878 & $\underline{26}$ & - & - & $?$ & Y \\
\hline 184 & 16185 & Acid Red 27; Food Red 9 & Monoazo & 1878 & $\underline{40}$ & 85.5 & 9.86 & $\underline{294}$ & Y \\
\hline 185 & 16255 & Acid Red 18 & Monoazo & 1878 & $\underline{32}$ & 30.0 & - & $\underline{289}$ & Y \\
\hline 189 & 15630 & Pigment Red 49 & Monoazo & 1899 & 8 & $\underline{282}$ & 0.220 & $\underline{353}$ & $\mathrm{~N}$ \\
\hline 193 & 15640 & Acid Red 10 & Monoazo & 1882 & 9 & $\underline{\underline{209}}$ & - & $?$ & $\mathrm{~N}$ \\
\hline 195 & 14095 & Mordant Yellow 3 & Monoazo & 1890 & $\underline{23}$ & $\underline{124}$ & 15.9 & 94.2 & $\mathrm{~N}$ \\
\hline 202 & 15705 & Mordant Black 17 & Monoazo & 1903 & $\underline{29}$ & $\underline{243}$ & 19.2 & $\underline{1523}$ & $\mathrm{~N}$ \\
\hline 203 & 14645 & Mordant Black 11 & Monoazo & 1904 & 11 & $\underline{130}$ & 87.2 & $\underline{303}$ & $\mathrm{~N}$ \\
\hline 204 & 15710 & Mordant Black 1 & Monoazo & 1904 & 12 & 96.6 & 87.3 & $\underline{687}$ & $\mathrm{~N}$ \\
\hline 208 & 13390 & Acid Blue 92 & Monoazo & 1897 & 11 & 45.0 & 8.62 & 454 & $\mathrm{~N}$ \\
\hline 216 & 16105 & Mordant Red 9; Pigment Red 60 & Monoazo & $?$ & 13 & - & 1.75 & $\underline{107}$ & $\mathrm{~N}$ \\
\hline 234 & 20170 & Acid Orange 24 & Disazo & 1881 & $\underline{20}$ & 13.2 & 5.24 & $\underline{169}$ & $\mathrm{~N}$ \\
\hline 241 & 20350 & Acid Black 17 & Disazo & 1891 & 5 & $\underline{291}$ & - & $?$ & $\mathrm{~N}$ \\
\hline 246 & 20470 & Acid Black 1 & Disazo & 1891 & $\underline{42}$ & $\underline{429}$ & 6.67 & $\underline{2609}$ & $\mathrm{Y}$ \\
\hline 248 & 26100 & Solvent Red 23 & Disazo & 1879 & $\underline{24}$ & - & - & $?$ & $\mathrm{~N}$ \\
\hline 252 & 27290 & Acid Red 73 & Disazo & 1882 & $\underline{19}$ & $\underline{123}$ & 3.06 & $\underline{158}$ & Y \\
\hline 258 & 26105 & Solvent Red 24 & Disazo & $?$ & $\underline{23}$ & - & - & 41.4 & $\mathrm{~N}$ \\
\hline 262 & $\begin{array}{c}27200 ; \text { see also } \\
27201 \\
\end{array}$ & Acid Red 115 & Disazo & 1879 & $\underline{15}$ & 13.2 & 0.550 & 51.8 & Y \\
\hline 280 & 26905 & Acid Red 66 & Disazo & 1879 & $\underline{17}$ & 36.6 & 2.34 & 74.2 & $\mathrm{~N}$ \\
\hline 289 & 26400 & Acid Blue 120 & Disazo & 1892 & $\underline{19}$ & $\underline{146}$ & $\underline{114}$ & $\underline{481}$ & $\mathrm{~N}$ \\
\hline 299 & $\begin{array}{c}26695 ; \text { see also } \\
26750 \text { and } 26751 \\
\end{array}$ & Mordant Black 5 & Disazo & 1889 & $\underline{24}$ & $\underline{460}$ & 13.7 & $\underline{223}$ & $\mathrm{~N}$ \\
\hline 307 & 26370 & Acid Black 24 & Disazo & 1902 & 10 & 69.6 & 2.40 & $\underline{150}$ & $\mathrm{~N}$ \\
\hline 308 & 26300 & Acid Black 7 & Disazo & 1888 & $\underline{18}$ & $\underline{152}$ & - & 43.0 & $\mathrm{~N}$ \\
\hline 311 & 27240 & & Disazo & 1885 & 12 & $\underline{168}$ & - & $?$ & $\mathrm{~N}$ \\
\hline 317 & 27725 & Direct Blue 132 & Disazo & 1893 & 1 & $\underline{306}$ & 17.3 & ? & $\mathrm{N}$ \\
\hline 326 & see $29150-29230$ & & Disazo & 1900 & 7 & 36.7 & 19.9 & $\underline{188}$ & $\mathrm{~N}$ \\
\hline 331 & 21000 & Basic Brown 1 & Disazo & $\underline{1863}$ & $\underline{47}$ & 27.6 & 0.114 & $\underline{514}$ & $\mathrm{Y}$ \\
\hline 332 & 21010 & Basic Brown 4 & Disazo & 1878 & $\underline{37}$ & $\underline{171}$ & - & $\underline{673}$ & $\mathrm{~N}$ \\
\hline 364 & 24890 & Direct Yellow 4 & Disazo & 1886 & $\underline{19}$ & $\underline{277}$ & 0.250 & 91.2 & $\mathrm{Y}$ \\
\hline 365 & 24895 & Direct Yellow 12 & Disazo & 1886 & $\underline{31}$ & $\underline{148}$ & 23.8 & $\underline{508}$ & $\mathrm{~N}$ \\
\hline 370 & 22120 & Direct Red 28 & Disazo & 1884 & $\underline{41}$ & 12.0 & 10.1 & $\underline{1503}$ & $\mathrm{Y}$ \\
\hline 375 & 22145 & Direct Red 10 & Disazo & 1886 & $\underline{25}$ & 39.7 & - & $\underline{243}$ & $\mathrm{~N}$ \\
\hline 376 & 22150 & Direct Red 17 & Disazo & 1891 & $\underline{17}$ & 46.1 & 6.20 & $?$ & $\mathrm{~N}$ \\
\hline 394 & 22570 & Direct Violet 1 & Disazo & 1889 & $\underline{29}$ & 13.1 & - & 92.5 & $\mathrm{~N}$ \\
\hline 401 & 22590 & Direct Blue 2 & Disazo & 1890 & $\underline{32}$ & $\underline{606}$ & 71.2 & $\underline{905}$ & $\mathrm{~N}$ \\
\hline 406 & 22610 & Direct Blue 6 & Disazo & 1890 & 48 & 19.0 & 1.10 & $\underline{1790}$ & $\mathrm{~N}$ \\
\hline 410 & 22250 & Direct Yellow 1 & Disazo & 1884 & $\underline{26}$ & - & - & 54.3 & $\mathrm{~N}$ \\
\hline 415 & 22130 & Direct Orange 8 & Disazo & 1887 & $\underline{16}$ & - & 1.20 & 96.5 & $\mathrm{~N}$ \\
\hline
\end{tabular}


Table 2 (continued)

\begin{tabular}{|c|c|c|c|c|c|c|c|c|c|}
\hline 419 & 22310 & Direct Red 1 & Disazo & 1889 & $\underline{35}$ & 47.7 & 14.1 & $\underline{139}$ & $\mathrm{~N}$ \\
\hline 420 & 22311 & Direct Brown 2 & Disazo & 1889 & $\underline{32}$ & 63.7 & - & $\underline{258}$ & $\mathrm{~N}$ \\
\hline 446 & 23370 & Direct Orange 10 & Disazo & 1886 & $\underline{20}$ & 19.9 & - & ? & $\mathrm{N}$ \\
\hline 448 & 23500 & Direct Red 2 & Disazo & 1884 & $\underline{42}$ & $\underline{342}$ & 10.5 & $\underline{618}$ & $\mathrm{~N}$ \\
\hline 461 & 23520 & Direct Violet 21 & Disazo & 1885 & $\underline{16}$ & - & - & - & $\mathrm{N}$ \\
\hline 472 & 23710 & Direct Blue 21 & Disazo & 1890 & $\underline{20}$ & - & - & 92.2 & $\mathrm{~N}$ \\
\hline 477 & 23850 & Direct Blue 14 & Disazo & 1890 & $\underline{30}$ & - & 1.10 & $\underline{216}$ & $\mathrm{~N}$ \\
\hline 478 & 23380 & Direct Orange 7 & Disazo & 1888 & $\underline{21}$ & 55.6 & 3.81 & $?$ & $\mathrm{~N}$ \\
\hline 495 & 24100 & Direct Red 7 & Disazo & 1885 & $\underline{26}$ & 47.7 & 4.30 & 41.3 & $\mathrm{~N}$ \\
\hline 502 & 24140 & Direct Blue 8 & Disazo & 1885 & $\underline{29}$ & 78.7 & 3.07 & $\underline{237}$ & $\mathrm{~N}$ \\
\hline 512 & 24280 & Direct Blue 22 & Disazo & 1894 & 9 & 15.2 & 1.46 & $\underline{112}$ & $\mathrm{~N}$ \\
\hline 518 & 24410 & Direct Blue 1 & Disazo & 1891 & $\underline{23}$ & $\underline{117}$ & 48.9 & $\underline{245}$ & $\mathrm{~N}$ \\
\hline 520 & 24400 & Direct Blue 15 & Disazo & 1890 & $\underline{35}$ & 12.9 & 7.51 & $\underline{223}$ & $\mathrm{~N}$ \\
\hline 539 & 31560 & Direct Black 9 & Trisazo & 1896 & 14 & 403 & 38.0 & $\underline{185}$ & $\mathrm{~N}$ \\
\hline 553 & 31820 & & Trisazo & 1896 & 2 & $\underline{146}$ & - & - & $\mathrm{N}$ \\
\hline 575 & 31940 & & Trisazo & 1893 & 3 & $\underline{144}$ & - & - & $\mathrm{N}$ \\
\hline 576 & 31955 & Direct Blue 30 & Trisazo & 1890 & 2 & 100 & 0.300 & $?$ & $\mathrm{~N}$ \\
\hline 581 & 30235 & Direct Black 38 & Trisazo & 1901 & $\underline{39}$ & $\underline{1238}$ & - & $\underline{7737}$ & $\mathrm{~N}$ \\
\hline 582 & 30245 & Direct Black 4 & Trisazo & 1901 & $\underline{24}$ & $\underline{249}$ & - & $\underline{2051}$ & $\mathrm{~N}$ \\
\hline 593 & 30295 & Direct Green 6 & Trisazo & 1891 & $\underline{43}$ & 76.6 & 33.3 & 420 & $\mathrm{~N}$ \\
\hline 594 & 30315 & Direct Green 8 & Trisazo & 1891 & $\underline{31}$ & - & 11.6 & $\underline{137}$ & $\mathrm{~N}$ \\
\hline 596 & 30045 & Direct Brown 1 & Trisazo & $?$ & $\underline{16}$ & 17.0 & - & $\underline{1000}$ & $\mathrm{~N}$ \\
\hline 598 & 30140 & Direct Brown 6 & Trisazo & 1888 & $\underline{15}$ & 48.7 & - & $\underline{245}$ & $\mathrm{~N}$ \\
\hline 606 & 35005 & Direct Brown 44 & Polyazo & 1887 & 7 & 41.9 & 17.7 & $\underline{138}$ & $\mathrm{~N}$ \\
\hline 620 & 40000 & Direct Yellow 11 & Stilbene & 1883 & $\underline{35}$ & $\underline{222}$ & 0.841 & $\underline{570}$ & $\mathrm{~N}$ \\
\hline 621 & $40015 ; 40002$ & Direct Orange 15 & Stilbene & 1888 & $\underline{22}$ & 24.7 & - & $\underline{147}$ & $\mathrm{~N}$ \\
\hline 622 & 40006 & Direct Yellow 6 & Stilbene & 1886 & $\underline{16}$ & 85.1 & - & $?$ & $\mathrm{~N}$ \\
\hline 636 & 18820 & Acid Yellow 11 & Pyrazolone & 1892 & 11 & 33.5 & 56.6 & $\underline{113}$ & $\mathrm{Y}$ \\
\hline 640 & 19140 & Acid Yellow 23; Food Yellow 4 & Pyrazolone & 1884 & $\underline{25}$ & $\underline{266}$ & $\underline{133}$ & $\underline{\underline{736}}$ & $\mathrm{Y}$ \\
\hline 655 & $41000 ; 41000 B$ & Basic Yellow 2; Solvent Yellow 34 & Ketonimine & 1883 & $\underline{18}$ & $\underline{449}$ & $\underline{127}$ & $\underline{471}$ & $Y$ \\
\hline 657 & $42000 ; 42000 B$ & Basic Green 4; Solvent Green 1 & Triphenylmethane & 1878 & $\underline{32}$ & $\underline{179}$ & 2.04 & $\underline{654}$ & $\mathrm{Y}$ \\
\hline 662 & 42040 & Basic Green 1 & Triphenylmethane & 1879 & $\underline{24}$ & 73.9 & 3.30 & $?$ & $Y$ \\
\hline 670 & 42095 & Acid Green 5; Food Green 2 & Triphenylmethane & 1879 & $\underline{18}$ & 71.4 & 12.2 & ? & $\mathrm{N}$ \\
\hline 677 & $42510 ; 42510 B$ & Basic Violet 14; Solvent Red 41 & Triphenylmethane & $\underline{1856}$ & $\underline{36}$ & 87.1 & 2.09 & $\underline{284}$ & $Y$ \\
\hline 679 & 42530 & & Triphenylmethane & $\underline{1863}$ & 12 & - & 1.05 & - & $\mathrm{N}$ \\
\hline 680 & $42535 ; 42535 B$ & Basic Violet 1; Solvent Violet 8 & Triphenylmethane & $\underline{1861}$ & $\underline{35}$ & $\underline{255}$ & 3.23 & $\underline{632}$ & $\mathrm{Y}$ \\
\hline 683 & 42536 & Basic Violet 13 & Triphenylmethane & $\underline{1866}$ & $\underline{17}$ & 22.4 & 0.095 & $?$ & $\mathrm{~N}$ \\
\hline 684 & 42585 & Basic Blue 20 & Triphenylmethane & 1871 & 5 & - & - & - & $\mathrm{N}$ \\
\hline 685 & 42590 & & Triphenylmethane & $\underline{1866}$ & 4 & - & - & - & $\mathrm{N}$ \\
\hline 686 & 42556 & & Triphenylmethane & $\underline{1866}$ & 0 & - & - & - & $\mathrm{N}$ \\
\hline 687 & 42515 & & Triphenylmethane & $\underline{1860}$ & 2 & - & - & - & $\mathrm{N}$ \\
\hline 688 & 42760 & Solvent Blue 23 & Triphenylmethane & $\underline{1866}$ & 5 & - & - & - & $\mathrm{N}$ \\
\hline 689 & 42775 & Solvent Blue 3 & Triphenylmethane & $\underline{1861}$ & $\underline{21}$ & 50.6 & - & 87.5 & $\mathrm{~N}$ \\
\hline 692 & 42685 & Acid Violet 19 & Triphenylmethane & 1877 & $\underline{22}$ & 19.1 & 4.85 & - & $\mathrm{N}$ \\
\hline 698 & 42650 & Acid Violet 17 & Triphenylmethane & 1890 & $\underline{21}$ & $\underline{154}$ & 45.2 & $\underline{148}$ & $\mathrm{~N}$ \\
\hline 703 & 42765 & Acid Blue 119 & Triphenylmethane & $\underline{1862}$ & $\underline{15}$ & - & - & ? & $\mathrm{N}$ \\
\hline 704 & 42750 & Acid Blue 110 & Triphenylmethane & $\underline{1862}$ & $\underline{29}$ & $\underline{287}$ & 65.4 & $\underline{155}$ & $Y$ \\
\hline 705 & 42770 & Acid Blue 48 & Triphenylmethane & $\underline{1862}$ & $\underline{16}$ & 31.5 & 1.82 & $?$ & $\mathrm{~N}$ \\
\hline 706 & 42780 & Acid Blue 93 & Triphenylmethane & $\underline{1862}$ & $\underline{18}$ & 45.0 & 2.15 & $?$ & $\mathrm{Y}$ \\
\hline
\end{tabular}


Table 2 (continued)

\begin{tabular}{|c|c|c|c|c|c|c|c|c|c|}
\hline 707 & 42755 & Acid Blue 22 & Triphenylmethane & $\underline{1862}$ & $\underline{31}$ & 86.5 & 6.72 & 98.8 & $\mathrm{~N}$ \\
\hline 712 & 42051 & Acid Blue 3 & Triphenylmethane & 1888 & 14 & $\underline{129}$ & 45.5 & ? & $\mathrm{N}$ \\
\hline 724 & 43800 & & Triphenylmethane & $\underline{1834}$ & 3 & - & 1.46 & ? & $\mathrm{N}$ \\
\hline 725 & 43875 & & Triphenylmethane & $\underline{1835}$ & 0 & - & - & - & $\mathrm{N}$ \\
\hline 728 & 44040 & Basic Blue 11 & Triphenylmethane & 1892 & 10 & $\underline{110}$ & 0.097 & ? & Y \\
\hline 736 & 44095 & Acid Blue 97 & Triphenylmethane & 1895 & 3 & $\underline{174}$ & 4.18 & $?$ & $\mathrm{~N}$ \\
\hline 737 & 44090 & Acid Green 50 & Triphenylmethane & 1883 & $\underline{16}$ & 44.9 & $\underline{342}$ & $\underline{376}$ & $\mathrm{~N}$ \\
\hline 749 & 45170 & Basic Violet 10 & Xanthene & 1887 & $\underline{20}$ & 58.3 & 20.3 & ? & Y \\
\hline 766 & 45350 & Acid Yellow 73 & Xanthene & 1871 & $\underline{17}$ & - & 0.725 & 2.4 & $Y$ \\
\hline 768 & 45380 & Acid Red 87 & Xanthene & 1871 & $\underline{23}$ & 94.5 & 0.209 & $\underline{161}$ & Y \\
\hline 771 & 45400 & Acid Red 91 & Xanthene & 1875 & $\underline{17}$ & 17.5 & - & - & $\mathrm{N}$ \\
\hline 773 & 45430 & Acid Red 51; Food Red 14 & Xanthene & 1876 & $\underline{17}$ & - & - & 7.3 & $\mathrm{Y}$ \\
\hline 793 & 46045 & Basic Orange 15 & Acridine & $\underline{1862}$ & $\underline{\underline{21}}$ & $\underline{155}$ & $\underline{126}$ & $\underline{123}$ & $\mathrm{~N}$ \\
\hline 801 & 47005 & Acid Yellow 3 & Quinoline & 1882 & $\underline{16}$ & 15.3 & 76.5 & 51.2 & $\mathrm{Y}$ \\
\hline 806 & & & Quinoline & $\underline{1856}$ & 2 & - & - & - & $\mathrm{N}$ \\
\hline 812 & 49000 & Direct Yellow 59 & Thiazole & 1887 & $\underline{26}$ & 56.2 & 33.1 & $\underline{271}$ & $\mathrm{~N}$ \\
\hline 813 & 19540 & Direct Yellow 9 & Thiazole & 1887 & $\underline{15}$ & 29.9 & 22.6 & 3.5 & $\mathrm{~N}$ \\
\hline 814 & 19555 & Direct Yellow 28 & Thiazole & 1887 & $\underline{23}$ & $\underline{\underline{175}}$ & 25.9 & $\underline{230}$ & $\mathrm{~N}$ \\
\hline 821 & 49700 & & Indophenol & 1881 & 1 & - & - & $\underline{127}$ & $\mathrm{~N}$ \\
\hline 841 & 50240 & Basic Red 2 & Azine & $\underline{1859}$ & $\underline{25}$ & 59.9 & 2.61 & $\underline{150}$ & Y \\
\hline 846 & 50245 & & Azine & $\underline{1856}$ & 2 & - & 0.057 & - & Y \\
\hline 857 & 50375 & Basic Red 6 & Azine & $\underline{1868}$ & 1 & - & - & - & $\mathrm{N}$ \\
\hline 860 & 50400 & Solvent Blue 7 & Azine & $\underline{1863}$ & $\underline{38}$ & 25.3 & - & $\underline{436}$ & $\mathrm{~N}$ \\
\hline 861 & 50405 & Acid Blue 20 & Azine & $\underline{1867}$ & $\underline{39}$ & 21.8 & - & $\underline{184}$ & $\mathrm{~N}$ \\
\hline 864 & 50415; 50415B & Solvent Black 5; Solvent Black 7 & Azine & $\underline{1867}$ & $\underline{44}$ & $\underline{187}$ & 0.220 & $\underline{919}$ & $\mathrm{~N}$ \\
\hline 865 & 50420 & Acid Black 2 & Azine & $\underline{1867}$ & $\underline{41}$ & $\underline{395}$ & 0.250 & $\underline{2743}$ & Y \\
\hline $870^{*}$ & 50440 & Oxidation Base 1; Pigment Black 1 & Aniline Black & $\underline{1834}$ & 1 & - & - & - & $\mathrm{N}$ \\
\hline 875 & see 76060 & Oxidation Base 10 & Aniline Black & 1888 & $\underline{15}$ & 53.7 & 0.300 & $\underline{168}$ & $\mathrm{~N}$ \\
\hline 883 & 51030 & Mordant Blue 10 & Oxazine & 1881 & $\underline{15}$ & - & 73.3 & $\underline{435}$ & $\mathrm{~N}$ \\
\hline 909 & 51175 & Basic Blue 6 & Oxazine & 1879 & $\underline{26}$ & 32.5 & 12.9 & 58.3 & $\mathrm{~N}$ \\
\hline 922 & 52015 & Basic Blue 9 & Thiazine & 1876 & $\underline{32}$ & $\underline{186}$ & 10.2 & $\underline{577}$ & Y \\
\hline 933 & $53210 ; 53000$ & & Sulphide & 1873 & 8 & - & 1.5 & - & $\mathrm{N}$ \\
\hline $969^{+}$ & 53630 & Vat Blue 43 & Sulphide & 1908 & 3 & $\underline{293}$ & $\underline{141}$ & - & $\mathrm{N}$ \\
\hline 978 & 53185 & Sulphur Black 1 & Sulphide & 1896 & $\underline{23}$ & $\underline{5615}$ & - & $\underline{16305}$ & $\mathrm{~N}$ \\
\hline 1016 & 55005 & & Hydroxyketone & $\underline{1828}$ & 1 & - & - & - & $\mathrm{N}$ \\
\hline 1019 & 57010 & Mordant Black 37 & Hydroxyketone & $\underline{1861}$ & 3 & $\underline{198}$ & 14.5 & - & $\mathrm{N}$ \\
\hline 1027 & 58000 & $\begin{array}{l}\text { Mordant Red 11; Pigment Red } 83 \\
\text { (lake) }\end{array}$ & Anthraquinone & $\underline{1868}$ & 10 & $\underline{202}$ & $\underline{348}$ & $?$ & Y \\
\hline 1034 & 58005 & Mordant Red 3 & Anthraquinone & 1871 & 6 & 81.9 & 34.2 & $?$ & $\mathrm{Y}$ \\
\hline 1035 & 58200 & Mordant Brown 42 & Anthraquinone & 1877 & 14 & $\underline{110}$ & 16.7 & $\underline{157}$ & $\mathrm{~N}$ \\
\hline 1043 & 58220 & & Anthraquinone & $\underline{1865}$ & 0 & - & - & - & $\mathrm{N}$ \\
\hline 1052 & 58600 & & Anthraquinone & $\underline{1835}$ & 1 & - & - & 0 & $\mathrm{~N}$ \\
\hline 1054 & 63010 & Acid Blue 45 & Anthraquinone & 1897 & 12 & - & 55.4 & $\underline{309}$ & $\mathrm{~N}$ \\
\hline 1062 & 58605 & Mordant Blue 32 & Anthraquinone & 1891 & 4 & $\underline{108}$ & $\underline{234}$ & 56.5 & $\mathrm{~N}$ \\
\hline 1066 & 67410 & & Anthraquinone & 1877 & 6 & $\underline{319}$ & 8.50 & 0 & $\mathrm{~N}$ \\
\hline 1067 & 67415 & Mordant Blue 27 & Anthraquinone & 1881 & 6 & $\underline{112}$ & 38.8 & 0 & $\mathrm{~N}$ \\
\hline 1069 & 67425 & & Anthraquinone & 1890 & 1 & $\underline{230}$ & - & 0 & $\mathrm{~N}$ \\
\hline 1070 & 67430 & & Anthraquinone & 1890 & 1 & $\underline{260}$ & 2.00 & 0 & $\mathrm{~N}$ \\
\hline 1071 & & & Anthraquinone & 1888 & 2 & $\underline{135}$ & 23.2 & 0 & $\mathrm{~N}$ \\
\hline 1107 & & & Anthraquinone Vat & 1901 & 0 & $\underline{187}$ & 9.68 & ? & $\mathrm{N}$ \\
\hline 1113 & 69825 & Vat Blue 6 & Anthraquinone Vat & 1903 & 6 & $\underline{479}$ & $\underline{367}$ & $?$ & $\mathrm{~N}$ \\
\hline 1177 & 73000 & Vat Blue 1 & Indigoid & 1890 & 13 & 8507 & - & $\underline{28347}$ & $\mathrm{~N}$ \\
\hline 1180 & 73015 & Acid Blue 74; Food Blue 1 & Indigoid & 1890 & 12 & 19.3 & 4.53 & $\underline{1877}$ & $Y$ \\
\hline 1184 & 73065 & Vat Blue 5 & Indigoid & 1907 & 8 & 16.9 & $\underline{299}$ & ? & $\mathrm{N}$ \\
\hline 1222 & 73620 & & Indigoid & 1906 & 1 & 19.8 & $\underline{190}$ & 0 & $\mathrm{~N}$ \\
\hline- & - & Aldehyde Green [14] & Triphenylmethane & 1862 & - & - & - & - & $\mathrm{N}$ \\
\hline - & - & Aldehyde Blue [17] & Triphenylmethane & 1861 & - & - & - & - & $\mathrm{N}$ \\
\hline
\end{tabular}

Underlined bold values indicate matches to the selection criteria

${ }^{*} \mathrm{Cl} \# 870$ may also be Cl\# 871 (from Schultz \# 922 in source data); ${ }^{\dagger} \mathrm{Cl} \# 969$ may also be Cl\# 970 or 971 (from Schultz \# 748 in source data) 
Table 3 US dye imports in 1914 [15] exceeding 100,000 lb, without Schultz number

\begin{tabular}{lll}
\hline Product Name & $\begin{array}{l}\text { Import Qty. } \\
\text { lb } \times 10^{3}\end{array}$ & Category \\
\hline Benzo Fast Black L. & 100 & Unidentified azo \\
Oxy Diamine Black (V. M.) & 147 & Unidentified azo \\
Oxy Diaminogen (V. M.) & 139 & Unidentified azo \\
Cotton Black (V. M.) & 300 & Unidentified azo \\
Lake Red (V. M.) & 349 & Unidentified azo \\
Zambesi Black (V. M.) & 629 & Unidentified azo \\
Wool Black (V. M.) & 119 & Unidentified \\
Amine Black (V. M.) & 146 & Unidentified \\
Black (V. M.) & 139 & Unidentified \\
\hline
\end{tabular}

V.M. indicates 'various markings' (e.g. 2B, BB etc)

For further comparison, Table 3 provides a supplementary list of ambiguous dyes that were listed in Norton's 1914 census [15] with import quantities above 100,000 lb. Six dyes were categorised as unidentified azo materials, while the remaining three were of unknown chemical class.

\section{Abbreviation \\ Cl: Colour Index.}

\section{Authors' contributions}

EH compiled the dataset used in this study, and drafted the manuscript. JP provided significant input through edits and revisions. Both authors worked on the interpretation of data, and the selection criteria for targeted analysis of colourants in future work. All authors read and approved the final manuscript.

\section{Funding}

Not applicable.

\section{Availability of data and materials}

The dataset generated and analysed during the current study is available in the Harvard Dataverse repository, https://doi.org/10.7910/DVN/BK2CBX [25].

\section{Competing interests}

The authors declare that they have no competing interests.

Received: 2 December 2020 Accepted: 30 January 2021

Published online: 20 March 2021

\section{References}

1. de Keijzer $\mathrm{M}$, et al. Indigo carmine: Understanding a problematic blue dye. Stud Conserv. 2012;57(sup 1):S87-95.

2. Rose RE. Growth of the dyestuffs industry: The application of science to art. J Chem Educ. 1926;3(9):973.

3. Welham RD. The Early History of the Synthetic Dye Industry I-The Chemical History. J Soc Dyers Colour. 1963;79(3):98-105.

4. Anft B. Friedlieb Ferinand Runge: A forgotten chemist of the nineteenth century. J Chem Educ. 1955;32(11):566.

5. Lecher HZ Early Synthetic Dyes. in Proceedings of the Perkin Centennial, 1856-1956. 1956. New York: American Association of Textile Chemists and Colorists.

6. Perkin WH. Hofmann Memorial Lecture. Journal of the Chemical Society, 1896. 69: p. 596-637.
7. Welham RD. The Early History of the Synthetic Dye Industry II-The Industrial History (1856-1900). J Soc Dyers Colour. 1963;79(4):146-52.

8. Welham RD. The Early History of the Synthetic Dye Industry III-The Industrial History (1900-1914). J Soc Dyers Colour. 1963;79(5):181-5.

9. Richardson $\mathrm{H}$. The development of the British dyestuffs industry before 1939. Scott J Polit Econ. 1964;11(2):110-29.

10. Fay IW. The Chemistry of the coal-tar dyes. London: Constable and Co.; 1911.

11. Green AG, The Analysis of Dyestuffs: And Their Identification in Dyed and Coloured Materials, Lake-pigments, Food-stuffs, Etc. 1916: C. Griffin.

12. Hurst GH. A Dictionary of the Coal Tar Colours. 1892, London: Heywood and $\mathrm{Co}$.

13. Knecht E, ed. The Chemistry of the Coal-Tar Colours: Translated from the German of Dr. R. Benedikt. 1886, George Bell and Sons: London.

14. Nietzki R. Chemistry of the organic dyestuffs. 1892, London: Gurney \& Jackson.

15. Norton TH. The Census of the Artificial Dyestuffs Used in The United States. Industrial Engineering Chemistry. 1916;8(11):1039-48.

16. Rowe F. The Colour Index. Bradford: Society of Dyers and Colourists; 1924.

17. Crace-Calvert F. Dyeing and Calico Printing. 3rd ed. 1878, Manchester: Palmer \& Howe.

18. Schweppe $H_{1}$ Practical Information for the Identification of Early Synthetic Dyes. 1987, Smithsonian Institution: Washington, DC.

19. Bowes A, Méthé E, Ballard MW. Important early synthetic dyes: chemistry, constitution, date, properties, M.W. Ballard, Editor. 1991, Smithsonian Institution: Washington D.C.

20. Barnett JC. Synthetic organic dyes, 1856-1901: an introductory literature review of their use and related issues in textile conservation. Stud Conserv. 2007:52(sup1):67-77.

21. Society of Dyers and Colourists. Colour Index. 2nd ed. Bradford: Author; 1956.

22. Society of Dyers and Colourists. Colour Index. 3rd ed. Bradford: Author; 1971.

23. United States Tariff Commission. Census of dyes and coal-tar chemicals, Author, Editor. 1918-1921, Government Printing Office: Washington, DC. p. 31-35.

24. United States Tariff Commission. Census of dyes and other synthetic organic chemicals, Author, Editor. 1922-1929, Government Printing Office: Washington, DC

25. [dataset] E, Hagan, Poulin J, Statistics of the early synthetic dye industry: compiled data. 2020: Harvard Dataverse.

26. Burdett BC. The Colour Index: The past, present and future of colorant classification. J Soc Dyers Colour. 1982;98(4):114-20.

27. Schultz G, Julius P. Tabellarische übersicht der künstlichen organischen farbstoffe. 1 ed. 1888, Berlin: R. Gaertner's Verlagsbuchhandlung, Hermann Heyfelder.

28. Schultz G, Julius P. Farbstofftabellen. 5th ed. 1914

29. Rocke AJ. It Began with a Daydream: The 150th Anniversary of the Kekule Benzene Structure. Angew Chem Int Ed. 2015:54(1):46-50.

30. Gardner WM, editor. The British coal tar industry, its origin, development, and decline. Philadelphia: J. B. Lippincott Company; 1915. p. 437.

31. Bloxam AG. Patent law in relation to the dyeing industry, The British coal tar industry, its origin, development, and decline, W.M. Gardner, Editor. 1915, J. B. Lippincott Company: Philadelphia. pp. 269-79.

32. Lauth C. On the new aniline dye, Violet de Paris. Laboratory. 1867;1:138-9.

33. Whittaker CM. Milestones in the Production of Synthetic Dyes for Cellulosic Fibres. J Soc Dyers Colour. 1951;67(12):492-4.

34. Hesse BC. Relieving the Dyestuff Crisis. Industrial Engineering Chemistry. 1914;6(11):953-3.

35. Little AD. The Dyestuff Situation and Its Lesson. Industrial Engineering Chemistry. 1915;7(3):237-9.

36. Dyer O. Old Dyer to the Rescue. Canadian Textile Journal. 1914;31(11):317-8.

37. Jensen WB, Professor Norton Gives a Lecture, in Notes from the Oesper Collections. 2012, University of Cincinnati: Cincinnati. p. 1-10.

\section{Publisher's note}

Springer Nature remains neutral with regard to jurisdictional claims in published maps and institutional affiliations. 